\title{
Occurrence of Fusarium commune and F. oxysporum in Horseradish Roots
}

\author{
J. M. Yu, Department of Plant Pathology and Microbiology, Texas A\&M University, College Station 77840; and M. Babadoost, \\ Department of Crop Sciences, University of Illinois, Urbana 61801
}

\begin{abstract}
Yu, J. M., and Babadoost, M. 2013. Occurrence of Fusarium commune and F. oxysporum in horseradish roots. Plant Dis. 97:453-460.

This study was conducted to investigate the etiology of internal discoloration of horseradish roots. Several species of Fusarium and Verticillium were isolated from internally discolored horseradish roots collected from commercial fields in Illinois and research plots in Wisconsin during 2008 and 2009. Eleven isolates of Fusarium, identified as Fusarium oxysporum based on morphological features, were characterized by DNA sequencing of the nuclear translation elongation factor $1 \alpha($ EF- $1 \alpha)$ and mitochondrial small-subunit ribosomal DNA (mtSSU rDNA). Maximum parsimony analyses of DNA sequences from these two regions and the combined data set revealed that six isolates were clearly separated into a common clade that contained $F$. commune, with the remaining five isolates being grouped into a common clade with $F$.

oxysporum. Based on the DNA sequence data, we considered the six isolates grouped into a common clade with $F$. commune to be $F$. commune. Pathogenicity tests of $F$. commune and $F$. oxysporum were conducted on two horseradish cultivars, '1573' and 'Big Top Western', in a greenhouse. Root segments were inoculated by dipping them in a conidial suspension and then growing them in pots in a greenhouse for 4 months. For plants inoculated with $F$. commune, internal root discoloration and root rot developed 1 month after inoculation and almost all roots of the plant were completely rotten 4 months after inoculation. Inoculation of the plants with $F$. oxysporum resulted in only internal root discoloration but not root rot symptoms. This is the first report of F. commune causing internal discoloration and root rot of horseradish.
\end{abstract}

Horseradish (Armoracia rusticana Gaertn., Mey. \& Scherb.), a member of the Brassicaceae family, is grown for its white, fleshy, and pungent roots, which are used as a condiment $(9,17,27)$. Approximately $50 \%$ of the total horseradish in the United States is grown in the Mississippi River Valley, near East St. Louis, IL $(5,26)$. Two other major horseradish production areas in the United States are Eau Claire, WI and Tule Lake, CA $(4,5)$.

Internal discoloration of horseradish roots occurs throughout the world and is the main limiting factor in the production of horseradish $(4,10,13,24)$. In the past 30 years, growers in North America have experienced significant reductions in the marketable yield of horseradish, resulting from internal discoloration and rotting of roots $(4,10)$. In Illinois, yield losses up to $100 \%$ in commercial fields, caused by internal discoloration and rotting of roots, have occurred (4).

Internal discoloration of horseradish root was first reported in Germany in the 1890s (24). Mueller et al. (21) reported Verticillium dahliae as the primary causal agent of internal discoloration of horseradish roots. In 1986, B. J. Jacobson (unpublished data) isolated Fusarium oxysporum from internally discolored horseradish roots in Illinois. Percich and Johnson (23) reported discoloration and rot of horseradish roots as a complex disease in Wisconsin, caused by $F$. roseum 'Acuminatum', $V$. dahlia, and Pseudomonas fluorescens. Eastburn and Chang (10) reported V. dahliae as the primary causal agent of root discoloration in Illinois. Babadoost et al. (4) concluded that internal root discoloration of horseradish is a disease complex, caused by at least three fungi: $V$. dahliae, V. longisporum, and F. solani.

Internal discoloration of the root begins with dark brown to black discoloration of the vascular system and gradually spreads to inward (core) and outward (cortex) areas in the root $(10,13,21)$. Internally discolored horseradish roots are useless for industrial purposes such as preparing horseradish sauce (4).

Gerber et al. (13), Mueller et al. (21), and Percich and Johnson (23) reported that internal root discoloration in horseradish is usu-

Corresponding author: M. Babadoost, E-mail: babadoos@illinois.edu

Accepted for publication 13 November 2012.

http://dx.doi.org/10.1094/PDIS-06-12-0538-RE

(C) 2013 The American Phytopathological Society ally followed by root rot. However, according to Percich and Johnson (23), infection by $V$. dahliae alone did not result in root rotting, and a combination of $V$. dahliae with $F$. roseum 'Acuminatum' caused root rot. Also, Atibalentja and Eastburn $(2,3)$ and Eastburn and Chang (10) did not report any root rot caused by $V$. dahliae. Furthermore, Babadoost et al. (4) did not observe any root rot caused by $V$. dahliae, $V$. longisporum, or $F$. solani. Although root rot is a major problem of horseradish in Illinois (5) and other horseradish-growing areas in North America (M. Babadoost, unpublished data), its causal agent is not yet determined. It was suspected that root rot of horseradish is caused by a Fusarium sp. other than $F$. solani.

F. commune is a recently characterized species closely related to the $F$. oxysporum species complex (28). This fungus has been isolated from soil and plants, including white pine, Douglas fir, carnation, corn, carrot, and barley (28). Recently, this fungus was also reported to cause crown and root rot in tomato (16) and root rot in forest nurseries $(18,30)$. The morphological differences between conidia and conidiophores of $F$. commune and $F$. oxysporum are subtle $(18,30)$ and may not provide reliable characteristics to morphologically distinguish these species from each other. DNA sequences from the translation elongation factor $1 \alpha(\mathrm{EF}-1 \alpha)$ and the mitochondrial small-subunit ribosomal DNA (mtSSU rDNA) regions have been shown to be suitable for distinguishing $F$. commune from $F$. oxysporum $(18,30)$.

During 2008 and 2009, Fusarium and Verticillium spp. were isolated from almost all horseradish roots collected from Illinois and Wisconsin. In addition to three previously-reported Fusarium spp. (F. oxysporum, F. acuminatum, and F. solani) in horseradish roots, $F$. commune has been isolated for the first time in the present study. The purpose of this study was to identify $F$. commune based on molecular characterization from roots of horseradish and to determine the association of $F$. commune and its sister taxon $F$. oxysporum with internal discoloration of horseradish roots.

\section{Materials and Methods}

Sampling and fungal isolation. During 2008 and 2009, 306 horseradish roots were collected from 20 commercial fields (10 fields each year) in Illinois at harvest. A minimum of 10 roots and a maximum of 20 roots were collected from each field, which included 72 roots from 'Big Top Western' (BTW) and 234 roots from '1573'. In addition, 120 roots were collected from horseradish 
research plots in Eau Clair, WI in 2008 and 2009 (60 roots each year), which included 40 and 80 roots from BTW and ' $15 \mathrm{~K}$ '. BTW, 1573, and $15 \mathrm{~K}$ are major horseradish cultivars grown in Illinois and Wisconsin. All collected roots had internal discoloration symptoms, with severity of discoloration of 5 to $50 \%$ at the cross-sections (2). The roots were either tested immediately for the presence of pathogens or stored at $4^{\circ} \mathrm{C}$ until they were tested within 2 months from the date of collection.

Fungal isolations were carried out on collected roots using the procedure developed by Babadoost et al. (4). A 5-cm segment was cut from the middle of each collected root. The outer layers (approximately $1 \mathrm{~mm}$ ) of the segments were peeled to remove fungal and bacterial contaminants on the root surface. The peeled segments were surface sterilized by dipping them in a $6 \% \mathrm{NaClO}$ (full-strength commercial bleach) solution for $1 \mathrm{~min}$ followed by dipping in a $95 \%$ ethanol concentration for $3 \mathrm{~min}$, then rinsed in sterile-distilled water (SDW) three times (1 min each). Each surface-sterilized segment was blotted with sterilized blotter paper, and five small segments ( $5 \mathrm{~mm}$ thick) from each root were cut and placed onto potato dextrose agar (PDA; Difco) with lactic acid (PDA-LA) in petri plates. PDA-LA was made by adding $4 \mathrm{ml}$ of $25 \%$ lactic acid to PDA after autoclaving and cooling the culture medium to $50^{\circ} \mathrm{C}$. The plates were incubated at 22 to $24^{\circ} \mathrm{C}$ with 12 $\mathrm{h}$ of light and $12 \mathrm{~h}$ of darkness for 15 days. After 5, 10, and 15 days of incubation, plates were examined and individual hyphal tips of the developing fungal colonies were removed and placed onto PDA in petri plates. The plates were incubated at 22 to $24^{\circ} \mathrm{C}$ for 8 days. Single-spore cultures were prepared from the isolates and the cultures were saved on PDA slants for further studies.

Using morphological characteristics, isolated fungi were first identified to genus. Isolates identified as Fusarium were then further identified to species based on their morphological characteristics $(7,14)$. Eleven isolates identified as $F$. oxysporum were selected for molecular analysis to verify their identification.

DNA extraction and polymerase chain reaction amplification. The isolates were cultured in potato dextrose broth (Difco) in flasks for 7 to 10 days at $25^{\circ} \mathrm{C}$ on a shaker. Mycelia were collected from the cultures by filtration and transferred to $1.5-\mathrm{ml}$ tubes. Total DNA was extracted from fungal mycelia using the Fast DNA Spin kit (MP Bio), according to the manufacturer's recommended protocol. The mtSSU rDNA and EF- $1 \alpha$ regions were amplified using primers NSM1/NSM2 (CAGCAGTGAGGAATATTGGTCAATG/ GCGGATCATCGAATTAAATAACAT) (20) and EF-1/EF-2 (ATGGGTAAGGARGACAAGAC/GGARGTACCAGTRATCATG TT) (22), respectively. A 50- $\mu$ l polymerase chain reaction (PCR) mixture was prepared, which contained $1 \times$ PCR buffer, $1.5 \mathrm{mM}$ $\mathrm{MgCl}_{2}, 200 \mu \mathrm{M}$ dNTPs, 5 pmol of each primer, 2 units of Taq polymerase (Promega Corp.), and $10 \mathrm{ng}$ of DNA extract.

The PCR conditions for mtSSU were initial denaturing at $94^{\circ} \mathrm{C}$ for $3 \mathrm{~min}$; 35 cycles of denaturing at $94^{\circ} \mathrm{C}$ for $35 \mathrm{~s}$, annealing at $52^{\circ} \mathrm{C}$ for $55 \mathrm{~s}$, and extension at $72^{\circ} \mathrm{C}$ for $2 \mathrm{~min}$; and final extension at $72^{\circ} \mathrm{C}$ for $5 \mathrm{~min}$. For EF-1 $\alpha$, the PCR conditions were initial denaturing at $94^{\circ} \mathrm{C}$ for $2 \mathrm{~min} ; 30$ cycles of DNA denaturing at $92^{\circ} \mathrm{C}$ for $1 \mathrm{~min}$, annealing at $55^{\circ} \mathrm{C}$ for $1 \mathrm{~min}$, and extension at $72^{\circ} \mathrm{C}$ for $1 \mathrm{~min}$; and final extension was at $72^{\circ} \mathrm{C}$ for $5 \mathrm{~min}$. All reactions were conducted with an MJ PTC-200 thermal cycler (MJ Research Inc.).

DNA sequencing and phylogenic analysis. The PCR products were purified using the Wizard SV gel and the PCR Clean-Up system (Promega Corp.), according to the manufacturer's protocol. Purified PCR products were sequenced in an automated sequencer at the Core DNA Sequencing Facility of the University of Illinois at Urbana-Champaign. Sequencing was performed using the same forward and reverse primer sets used for the PCR amplification (32).

Raw sequences from both strands were aligned and edited using BioEdit version 7.0.9 (15). Using BLAST, the edited sequences were compared to the ID region available in the National Center for Biotechnology Information GenBank database (http:// www.ncbi.nlm.nih.gov). Sequences generated from materials in this study and retrieved from GenBank were aligned using the program CLUSTAL X (31) and the alignment was refined using PHYDIT version 3.2 (http://plaza.snu.ac.kr/ jchun/phydit) (8). Maximum parsimony analysis was estimated using heuristic searches consisting of random addition and tree bisectionreconnection branch swapping. Bootstrap analysis using 1,000 replications was performed to assess the relative stability of the branches. The sequences used in this analysis were deposited in GenBank (Table 1).

Pathogenicity tests. Pathogenicity tests were conducted using a root-dip inoculation method of Babadoost et al. (4) and Eastburn and Chang (10). Two isolates each of $F$. commune and $F$. oxysporum identified by morphological and molecular methods were tested for pathogenicity on 1573 and BTW horseradish.

Asymptomatic horseradish sets of 1573 and BTW were obtained from commercial growers. To eliminate possible set-borne inoculum, the sets were treated at $47^{\circ} \mathrm{C}$ for $20 \mathrm{~min}$ (11) prior to inoculation. The sets were dipped in $70 \%$ ethanol for $25 \mathrm{~s}$, soaked in $0.6 \%$ $\mathrm{NaClO}$ solution for $5 \mathrm{~min}$, and rinsed in tap water. Segments were then planted in 50-by-35-by-10-cm pots containing a pasteurized mix of soil/peat/perlite $(1: 1: 1)(4,10)$, and were grown in a greenhouse at 20 to $26^{\circ} \mathrm{C}$. After 30 days, plants were removed from the pots, soil was gently removed from the roots, and roots were inoculated with Fusarium isolates.

$F$. commune and $F$. oxysporum isolates were grown on PDA in 90-mm petri plates in an incubator at $24^{\circ} \mathrm{C}$ with $12 \mathrm{~h}$ of light and $12 \mathrm{~h}$ of darkness. A conidial suspension of each isolate was prepared from 10-day-old cultures by adding $10 \mathrm{ml}$ of SDW to each plate and dislodging the conidia using a soft brush. The concentration of conidia (macroconidia and microconidia) was adjusted to $10^{5}$ spores/ml using a hemocytometer (4). To prepare the sticky inoculum suspension, Fusarium inoculum was prepared in a sterilized $0.5 \%$ agar solution (2).

Roots of plants grown in the greenhouse were inoculated by dipping them in the $0.5 \%$ agar suspension of conidia for $15 \mathrm{~s}$. Inoculated plants were planted in plastic pots $(50$ by 35 by $10-\mathrm{cm})$ containing the pasteurized soil/peat/perlite (1:1:1) mix. Roots of

Table 1. Isolates of Fusarium commune and F. oxysporum from horseradish roots collected from Illinois and Wisconsin in 2008 and 2009

\begin{tabular}{|c|c|c|c|c|c|}
\hline \multirow[b]{2}{*}{ Identified species } & \multirow[b]{2}{*}{ Isolate } & \multirow[b]{2}{*}{ Horseradish cultivar } & \multirow[b]{2}{*}{ Geographic origin } & \multicolumn{2}{|c|}{ GenBank accession number ${ }^{\mathrm{Z}}$} \\
\hline & & & & NMS & EF-1 $\alpha$ \\
\hline F. commune & SD4139 & 1573 & Illinois & HM804944 & HM804935 \\
\hline F. commune & SC4015 & Big Top Western & Illinois & HM804946 & HM804937 \\
\hline F. commune & SC4025 & Big Top Western & Illinois & HM804947 & HM804938 \\
\hline F. commune & WA4023 & $15 \mathrm{~K}$ & Wisconsin & HM804948 & HM804939 \\
\hline F. commune & WA4069 & $15 \mathrm{~K}$ & Wisconsin & HM804949 & HM804940 \\
\hline F. comтипе & WB4031 & Big Top Western & Wisconsin & HM804950 & HM804941 \\
\hline F. oxysporum & SD3183 & 1573 & Illinois & HQ114271 & HQ114266 \\
\hline F. oxysporum & WA3037 & $15 \mathrm{~K}$ & Wisconsin & HQ114272 & HQ114267 \\
\hline F. oxysporum & WA3065 & $15 \mathrm{~K}$ & Wisconsin & HQ114273 & HQ114268 \\
\hline F. oxysporum & SD3152 & 1573 & Illinois & HQ114274 & HQ114269 \\
\hline F. oxysporum & WA3008 & $15 \mathrm{~K}$ & Wisconsin & HQ114275 & HQ114270 \\
\hline
\end{tabular}

${ }^{\mathrm{z}} \mathrm{NMS}=$ mitochondrial small-subunit ribosomal DNA and EF-1 $\alpha=$ translation elongation factor $1 \alpha$. 
control plants were dipped in sterilized $0.5 \%$ agar solution. Pots were placed in the greenhouse at 20 to $26^{\circ} \mathrm{C}$ under a combination of 1,000-W high-pressure sodium and mercury vapor lamps with a photoperiod of $12 \mathrm{~h}$ per day. Each inoculation treatment included six replications, with four plants in each replication. The experiment was performed twice.

Six plants were removed at monthly intervals until 4 months after inoculation. Roots were washed, cut, and assessed for severity of internal discoloration at the cross-section at the middle of the root, as described by Babadoost et al. (4). Severity of discoloration was rated using a scale of 0 to 4 , where $0=$ no discoloration and 1 $=1$ to $10(5.0), 2=11$ to $25(17.5), 3=26$ to 50 (37.5), and $4=51$ to $100 \%(75 \%)$ discoloration of root in the cross-section. The root sections were then used for pathogen isolation as previously described. Species of the isolated fungi from greenhouse-grown roots were identified using morphological characteristics and molecular methods reported by Skovgaard et al. (28), as previously described. Each pathogen was reisolated from its respective inoculated plant in both pathogenicity assays (data not shown).

Statistical methods. Statistical analyses were performed using SAS 9.3 (SAS Institute). Incidence and severity of the internal discoloration of the roots and incidence of root rot were analyzed using analysis of variance procedures. To calculate and compare severity of the internal root discoloration, the average of each severity index was considered, as follows: $0=0.0,1=5.0,2=$ $17.5,3=37.5$, and $4=75.0 \%$

\section{Results}

Morphological identification of fungi. Fungi were isolated from 357 of 426 roots, which included 250 of 306 and 107 of 120 roots collected from Illinois and Wisconsin, respectively. In total, 444 fungal isolates were collected, which comprised 328 and 116 isolates from Illinois and Wisconsin, respectively. Two and occasionally three different fungal species were isolated from some of the roots. Based on morphological characteristics, isolated fungi belong to seven genera, including Alternaria, Colletotrichum, Fusarium, Penicillium, Pyrenochaeta, Rhizopus, and Verticillium $(1,6)$. The most commonly isolated genera were Verticillium and Fusarium. Verticillium spp. were isolated from 45 and $22 \%$ of roots collected from Illinois and Wisconsin, respectively. In contrast, Fusarium spp. were isolated from 31 and $64 \%$ of roots collected from Illinois and Wisconsin, respectively. In total, 175 isolates were identified as Fusarium. Isolated Fusarium spp. included F. acuminatum, F. equiseti, F. oxysporum complex, F. proliferatum, and $F$. solani $(19,28)$, with $72,12,32,3$, and 59 of isolates, respectively (data not shown). F. solani was the most frequently isolated species (43\%) from samples collected from Illinois. In contrast, $F$. acuminatum was the most frequently isolated species (57\%) from roots collected from Wisconsin (data not shown). Eleven isolates (five from Illinois and six from Wisconsin) identified as $F$. oxysporum based on morphological characteristics were selected for molecular species identification.

Phylogenetic analysis. The PCR amplification of the mtSSU rDNA region for all 11 isolates generated 687- to 715-bp fragments, and alignment of the sequences resulted in a dataset of 643 characters. Based on 38 parsimony-informative characters, three most-parsimonious trees were located with tree length of 76 steps (consistency index $[\mathrm{CI}]=0.8947$, retention index $[\mathrm{RI}]=0.9590$; Fig. 1). All 11 isolates of Fusarium used in this study, morphologically placed in the $F$. oxysporum species complex, were

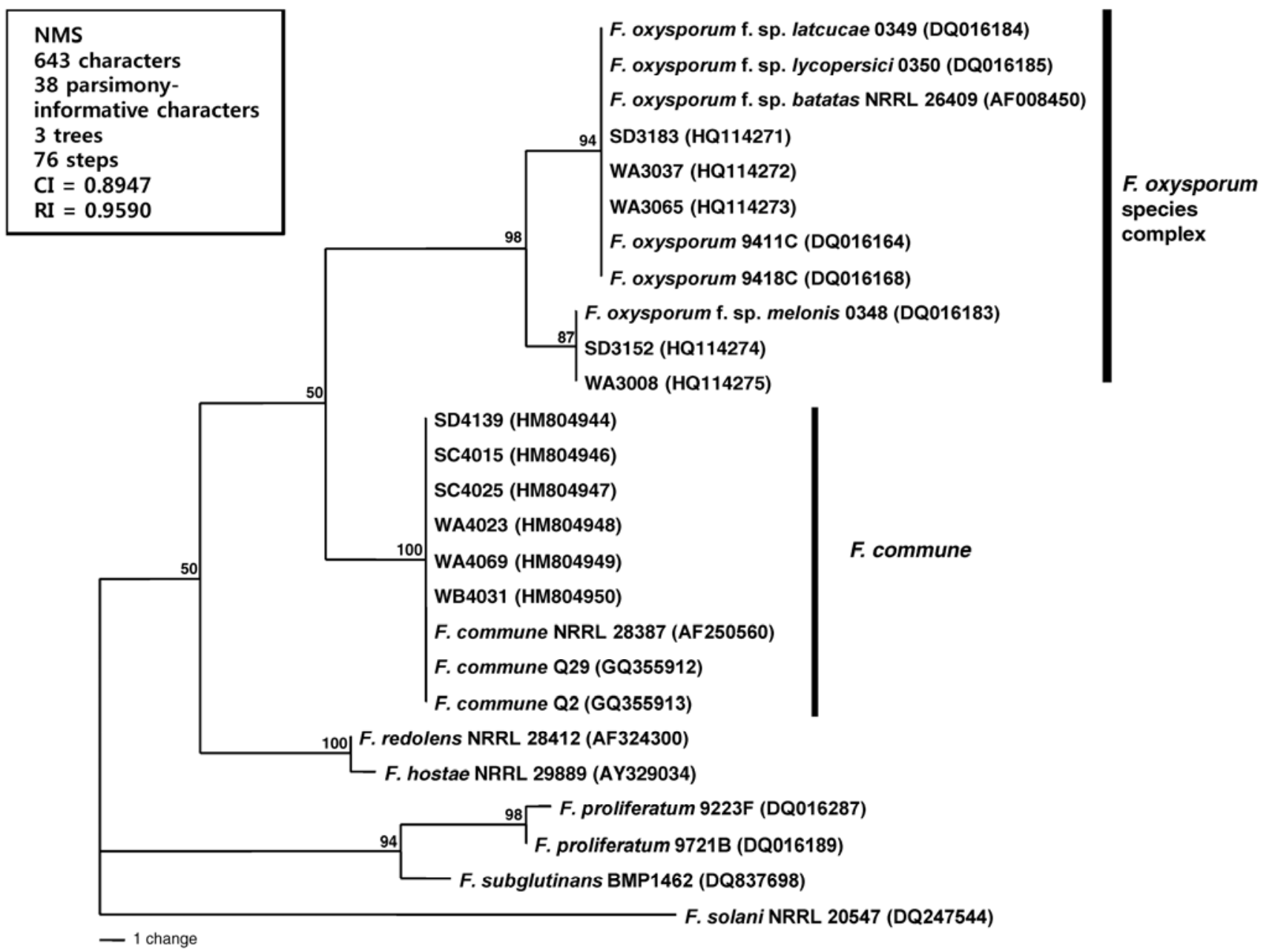

Fig. 1. One of three parsimonious trees inferred from sequence of mitochondrial small-subunit ribosomal DNA (NMS) gene of Fusarium spp. Numbers next to branches represent bootstrap values of 1,000 replicates calculated with maximum parsimony. Only bootstrap values higher than $50 \%$ are shown. 
divided into two clades. The first clade included six isolates along with reference strains of $F$. commune (NRR28387, Q2, and Q29), with strong bootstrap support (100\%). The second clade contained five isolates and reference strains of the $F$. oxysporum species complex (0349, 0350, 9411C, 9418C, and NRRL26409), with strong bootstrap value (98\%) (Fig. 2). The mtSSU rDNA sequences of the six isolates were deposited in the GenBank under the accession numbers HM804944 to HM804950 for $F$. commune and HQ114271 to HQ114275 for F. oxysporum (Table 1).

The PCR amplification of EF- $1 \alpha$ for all 11 isolates generated 623- to 646-bp fragments, and alignment resulted in a 624-character dataset. Based on 85 parsimony-informative characters, 12 most-parsimonious trees were generated with tree length of 201 steps $(\mathrm{CI}=0.8905, \mathrm{RI}=0.9275)$. The EF- $1 \alpha$ trees had topology similar to that revealed in analysis of the mtSSU sequences, except with greater genetic diversity among isolates of the two clades. Six isolates fell into four distinct groups, including reference strains of F. commune (NRR28387, Q2, and Q29), and formed a monophyletic clade with strong bootstrap support (100\%). The second clade included five isolates and reference strains of $F$. oxysporum species complex (0348, 0349, 0350, 9411C, 9418C, and NRRL26409), which were supported with strong bootstrap value (100\%) (Fig. 3). The full lengths of EF- $1 \alpha$ sequences of the isolates were deposited in GenBank under accession numbers HM804935 to HM804941 for $F$. commune and HQ114266 to HQ114270 for $F$. oxysporum (Table 1).

Phylogenetic analysis based on combined sequences of mtSSU rDNA and EF- $1 \alpha$ yielded four most-parsimonious trees (steps =
$278, \mathrm{CI}=0.8885, \mathrm{RI}=0.9369)$. Parsimony analysis of the combined dataset revealed a tree with topology similar to that revealed in independent analyses of mtSSU rDNA and EF-1 $\alpha$ (Fig. 3). All isolates were divided into two distinct clades: one contained six isolates $(F$. commune $)$ and the other five isolates $(F$. oxysporum). Sequences of $F$. commune strains (NRRL28387, Q2, and Q29) obtained from GenBank clustered together with six isolates of Fusarium from horseradish roots with strong bootstrap support (100\%), whereas sequences of $F$. oxysporum species complex strains (NRRL26409, 0348, 0349, 0350, 9411C, and 9418C) obtained from GenBank clustered together with five separate isolates of Fusarium from horseradish with strong bootstrap value (100\%). The phylogenetic tree revealed complete separation between isolates of $F$. commune and the $F$. oxysporum species complex, and indicated that six of the isolates of Fusarium (SC4015, SC4025, SD4139, WA4023, WA4069, and WB4031) from horseradish roots were $F$. commune, distinguished from its sister taxon $F$. oxysporum (28).

Pathogenicity. There was no significant difference in the incidence or severity of root discoloration and rot among two isolates of each pathogen used separately or combined together to inoculate plants.

All of the roots inoculated with $F$. commune were diseased 4 months after inoculation (Table 2; Fig. 4). Incidence of internal discoloration and root rot increased significantly by time over the period of 4 months. Internal discoloration was observed 1 month after inoculation of roots (Fig. 4C), and root rot was observed 2 months after inoculation (Fig. 4D). Three months after inoculation,

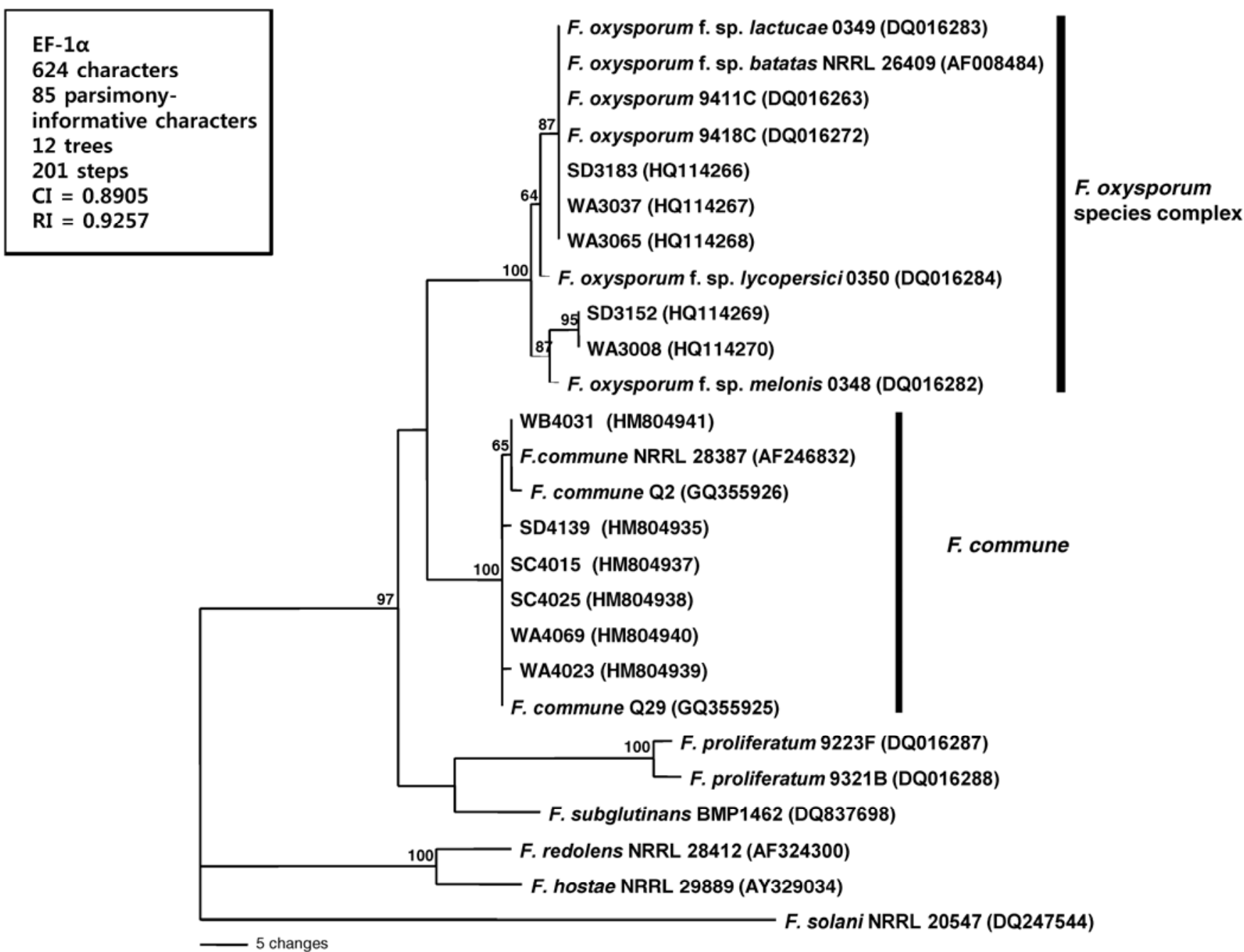

Fig. 2. One of 12 parsimonious trees inferred from sequence of translation elongation factor $1 \alpha$ (EF-1 $\alpha$ ) gene of Fusarium spp. Numbers next to branches represent bootstrap values of 1,000 replicates calculated with maximum parsimony. Only bootstrap values higher than $50 \%$ are shown. 
roots of 100 and $83.3 \%$ of plants of 1573 and BTW, respectively, were either internally discolored or rotten. Four months after inoculation, roots of $100 \%$ of plants of 1573 were rotten and roots of 16.7 and $83.3 \%$ of plants of BTW were internally discolored and rotten, respectively. Severity of internal discoloration in inoculated plants increased significantly over the 3 -month period. F. commune was isolated from all inoculated symptomatic roots of both cultivars. Isolation of the pathogen from most of the completely rotten main roots was not possible. However, the fungus was isolated from symptomatic lateral roots of the rotten main roots.

\begin{tabular}{|l|}
\hline EF-1 $\alpha+$ NMS \\
1267 characters \\
123 parsimony- \\
informative \\
characters \\
4 trees \\
278 steps \\
CI $=0.8850$ \\
RI $=0.9369$ \\
\hline
\end{tabular}

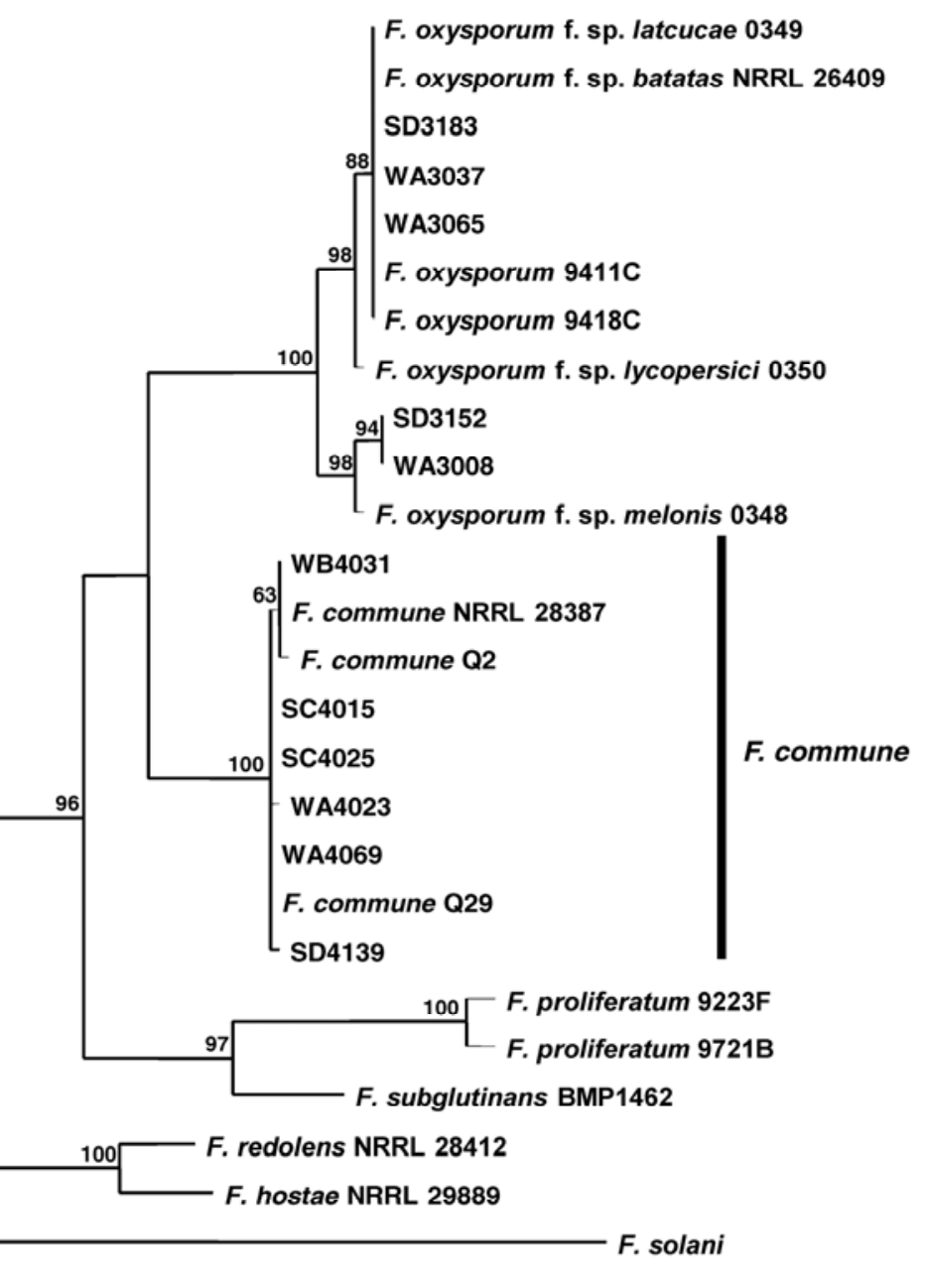

Fig. 3. One of four parsimonious trees based on the combined analysis of mitochondrial small-subunit ribosomal DNA (NMS) and translation elongation factor $1 \alpha$ (EF-1 $\alpha$ ) gene sequences from Fusarium spp. Numbers next to branches represent bootstrap values of 1,000 replicates calculated with maximum parsimony. Only bootstrap values higher than $50 \%$ are shown.

Table 2. Occurrence of internal root discoloration and root rot caused by artificial inoculation of Fusarium commune and F. oxysporum on horseradish '1573' and 'Big Top Western'

\begin{tabular}{|c|c|c|c|c|c|c|c|c|c|c|c|c|}
\hline \multirow[b]{3}{*}{ Treatment $^{\mathrm{x}}$} & \multirow[b]{3}{*}{ Disease $^{y}$} & \multirow[b]{3}{*}{ Occurrence $^{\mathrm{z}}$} & \multicolumn{10}{|c|}{ Disease development in months ${ }^{w}$} \\
\hline & & & \multicolumn{5}{|c|}{1573} & \multicolumn{5}{|c|}{ Big Top Western } \\
\hline & & & 1 & 2 & 3 & 4 & LSD & 1 & 2 & 3 & 4 & LSD \\
\hline \multirow[t]{4}{*}{ F. commune } & IRD & Incidence & 33.3 & 58.3 & 50.0 & 0.0 & NS & 33.3 & 25.0 & 33.3 & 16.7 & NS \\
\hline & & Severity & $1.7 \mathrm{ab}$ & $8.9 \mathrm{bc}$ & $11.7 \mathrm{c}$ & $0.0 \mathrm{a}$ & 7.7 & 1.7 & 3.0 & 4.0 & 14.5 & NS \\
\hline & $\mathrm{RR}$ & Incidence & $0.0 \mathrm{a}$ & $16.7 \mathrm{a}$ & $50.0 \mathrm{~b}$ & $100 \mathrm{c}$ & 26.8 & $0.0 \mathrm{a}$ & $33.3 \mathrm{ab}$ & $50.0 \mathrm{ab}$ & $83.3 \mathrm{c}$ & 33.6 \\
\hline & IRD+RR & Incidence & $33.3 \mathrm{a}$ & $75.0 \mathrm{~b}$ & $100 \mathrm{~b}$ & $100 \mathrm{~b}$ & 27.5 & $33.3 \mathrm{a}$ & $58.3 \mathrm{ab}$ & $83.3 \mathrm{bc}$ & $100 \mathrm{c}$ & 33.4 \\
\hline \multirow[t]{3}{*}{ F. oxysporum } & IRD & Incidence & $16.7 \mathrm{a}$ & $58.3 \mathrm{~b}$ & $83.3 \mathrm{bc}$ & $91.7 \mathrm{bc}$ & 33.2 & $16.7 \mathrm{a}$ & $41.7 \mathrm{a}$ & $83.3 \mathrm{~b}$ & $83.3 \mathrm{~b}$ & 34.9 \\
\hline & & Severity & $0.8 \mathrm{a}$ & $7.42 \mathrm{ab}$ & $15.2 \mathrm{bc}$ & $25.3 \mathrm{c}$ & 8.6 & $0.8 \mathrm{a}$ & $6.4 \mathrm{~b}$ & $12.3 \mathrm{~b}$ & $33.7 \mathrm{c}$ & 14.6 \\
\hline & $\mathrm{RR}$ & Incidence & 0.0 & 0.0 & 0.0 & 0.0 & NS & 0.0 & 0.0 & 0.0 & 0.0 & NS \\
\hline \multirow{3}{*}{ Control } & IRD & Incidence & 0 & 0 & 8.3 & 16.7 & NS & 0 & 0 & 0 & 8.3 & NS \\
\hline & & Severity & 0 & 0 & 0.4 & 0.8 & NS & 0 & 0 & 0 & 1.5 & NS \\
\hline & $\mathrm{RR}$ & Incidence & 0 & 0 & 0 & 0 & NS & 0 & 0 & 0 & 0 & NS \\
\hline
\end{tabular}


Internal discoloration developed in the roots inoculated with $F$. oxysporum isolates (Fig. 2B). The symptoms were observed 1 month after inoculation of roots and incidence of root discoloration was $83.3 \%$ in both cultivars by the end of 4 months from inoculation (Table 2). Severity of the discoloration increased over time but averages of the discoloration severity in treatments were less than those of $F$. commune and did not exceed $3 \%$ in the cross-sections of the roots. No root rot was observed in the roots inoculated with F. oxysporum isolates.

At 4 months after inoculation, roots of more than $83.3 \%$ of uninoculated plants were asymptomatic (Fig. 4A). However, 16.7 and $8.3 \%$ of roots of control plants of 1573 and BTW, respectively, showed minor internal discoloration in core areas of roots. Neither F. commune nor any other pathogens were isolated from these roots or any of the asymptomatic roots. Similar discoloration has been observed in some commercial fields with no detection of pathogens in the roots.

\section{Discussion}

We isolated six species of Fusarium ( $F$. acuminatum, F. commune, $F$. equiseti, $F$. oxysporum, $F$. proliferatum, and $F$. solani) from internally discolored horseradish roots. We also found that $F$. commune caused not only internal discoloration but also rot of horseradish roots. Previous investigators have reported $V$. dahliae
$(10,21,23)$, V. longisporum (4), F. acuminatum (F. roseum 'Acuminatum') (23), and F. solani (4) as the causal agents of the internal discoloration of horseradish roots. Also, B. J. Jacobson (unpublished data) isolated $F$. oxysporum from internally discolored roots in Illinois. However, he did not report its pathogenicity in horseradish. In this study, we identified $F$. commune in horseradish roots as a sister taxon of $F$. oxysporum based on sequence analyses of EF- $1 \alpha$ and mtSSU rDNA regions.

F. commune was described as a distinct species in 2003 (28). Morphological characteristics of $F$. commune are very similar to $F$. oxysporum and isolates of this fungus had been identified as $F$. oxysporum until 2003. Both species produce conidia on short monophialides in false heads on the aerial mycelium and chlamydospores singly or in pairs (28). The only distinct morphological characteristics to separate $F$. commune from $F$. oxysporum are the presence of long, slender monophialides in addition to the occasional production of polyphialides (28). However these morphological differences are subtle and can be variable $(18,30)$. Thus, morphological characteristics may not be adequate to distinguish $F$. commune from $F$. oxysporum and DNA sequencing of EF- $1 \alpha$ and mtSSU rDNA for identification of these two species is essential, as previously concluded by other investigators $(12,18,28,30)$. In this study, we also used DNA sequences of the two regions (EF- $1 \alpha$ and $\mathrm{mtSSU}$ ) and a combined data set to identify $F$. commune and $F$.
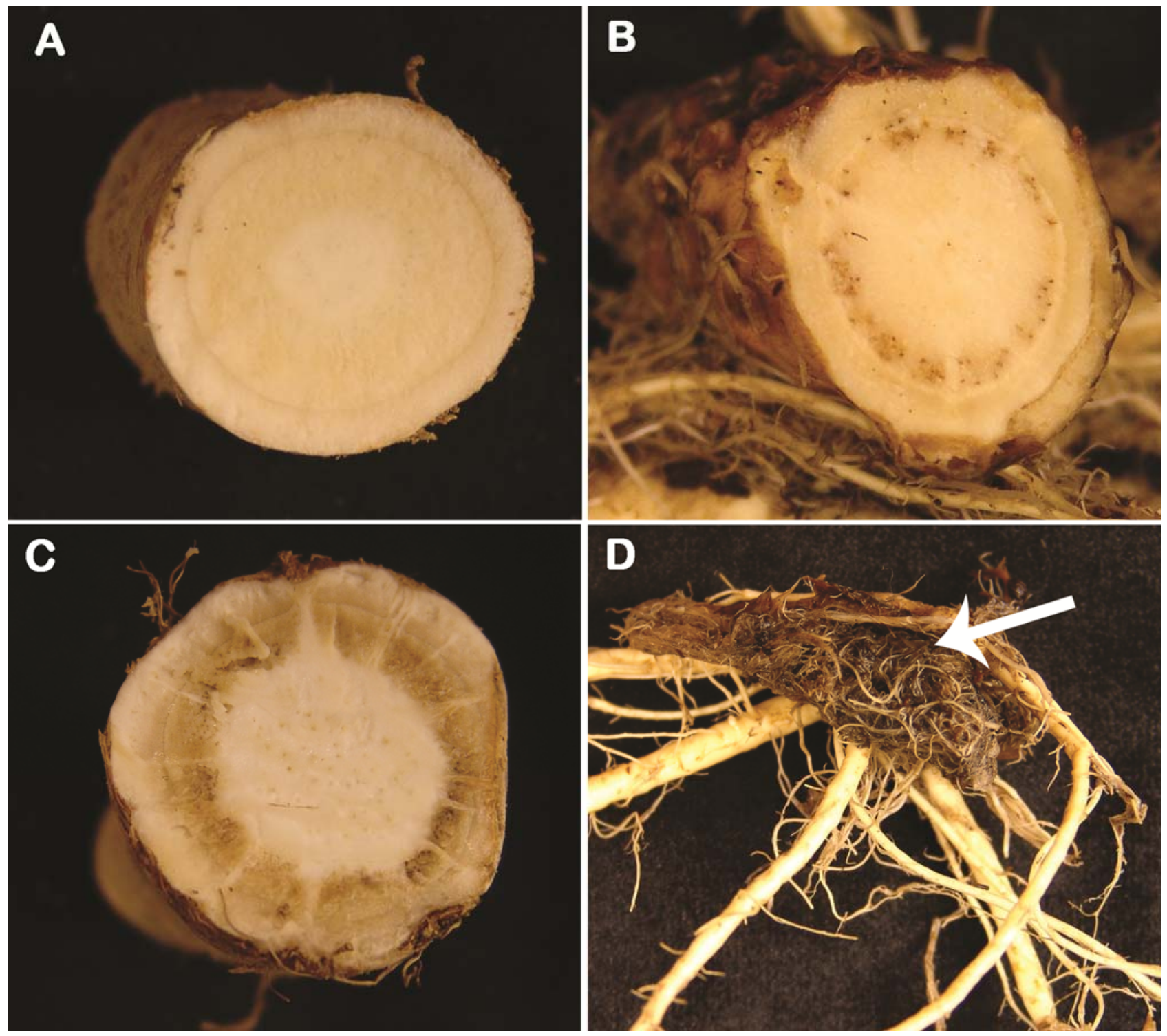

Fig. 4. A, Cross-section of an asymptomatic horseradish root; B, cross-section of a horseradish root with internal discoloration caused by Fusarium oxysporum; C, crosssection of a horseradish root with internal discoloration caused by F. commune; $\mathbf{D}$, rot of main root caused by F. commune. 
oxysporum. F. commune has been reported as an agent of root rot in white pine, Douglas fir, carnation, corn, carrot, and barley (28); root rot in forest nurseries $(18,29)$; and crown and root rot in tomato (16). This is the first report of the occurrence of $F$. commune in horseradish as a root pathogen.

Isolates of $F$. commune caused both internal root discoloration and severe root rot in horseradish. In contrast, $F$. oxysporum caused only internal root discoloration. The isolate, morphologically identified as $F$. equiseti, caused mild internal discoloration but $F$. proliferatum did not cause visible symptoms in horseradish roots in greenhouse studies (data not presented). Further studies are needed to fully address the importance of $F$. equiseti and $F$. proliferatum in horseradish roots.

Internal root discoloration is the most destructive disease of horseradish in North America $(2-4,10,11,21,23)$. This problem is now known as the "internal discoloration complex" of horseradish roots. Despite numerous attempts to determine specific symptoms of the internal discoloration complex of horseradish roots caused by each of the above-mentioned pathogenic Verticillium and Fusarium spp., we have not yet been able to establish species-specific symptom characteristics. Our studies show that internal discoloration of horseradish root begins with dark brown discoloration of vascular system and spreads to inward (core) and outward (cortex) areas. Further studies might result in identification of pathogen-specific symptoms of the internal discoloration of horseradish roots.

Previous researchers reported that foliar symptoms may be used as an initial indicator of internal discoloration of horseradish root $(2,10)$. The major foliage symptom described for this purpose is yellow spots on leaves that start near the leaf margins and progress inward along the veins, resulting in characteristic $\mathrm{V}$-shaped lesions. However, Eastburn and Chang (10) reported that foliar symptoms do not develop in all plants with internally discolored roots. We have rarely observed yellowing foliage symptoms in horseradish plants with discolored roots. Although foliage yellowing may develop in plants with discolored roots in certain cultivars, foliage symptoms are not reliable indications of root discoloration in horseradish. Major symptoms that we have observed in foliage of plants with internally discolored roots in research plots and commercial fields are wilting followed by the death of foliage. These symptoms are caused both by brittle root (Spiroplasma citri) $(5,25)$ and root rot $(5)$.

A greater than $20 \%$ incidence of root rot has been observed in some commercial horseradish fields in Illinois (5). Although various fungi and bacteria have been isolated from the rotten horseradish roots, the causal agent of the root rot had never been confirmed until now. It is apparent that $F$. commune is a causal agent of root rot of horseradish. In our studies, none of the Verticillium spp. or other Fusarium spp. isolated from horseradish roots caused root rot. However, some roots infected by Verticillium and Fusarium spp. may be colonized by opportunistic fungi or bacteria and result in root rot.

In our study, F. commune was isolated from 17 of 426 (4\%) of internally discolored horseradish roots (data not shown). Low incidence of $F$. commune in horseradish roots may indicate less importance of this pathogen in horseradish. As the results of our greenhouse experiments showed, roots of more than $83 \%$ of plants inoculated with $F$. commune rotted 4 months after inoculation. Because we collected horseradish root samples at harvest (approximately 5 months after planting propagative roots), it is highly likely that a majority of infected roots with $F$. commune had been rotten before harvest, as we commonly observed in our research plots as well as in commercial fields (5; M. Babadoost, unpublished data). To determine the accurate incidence of $F$. commune in commercial horseradish fields, multi-year studies of monthly sampling of horseradish roots in the fields beginning about 1 month after planting propagative roots is needed.

\section{Acknowledgments}

This research was supported, in part, by funds from North Central Integrated Pest Management Program. We thank Illinois Horseradish Growers Association and K. Traaseth from Wisconsin for providing horseradish roots and field facilities for field trials.

\section{Literature Cited}

1. Alexopoulos, C. J., Mims, C. W., and Blackwell, M. 1996. Introductory Mycology. John Wiley and Sons, Inc., New York.

2. Atibalentja, N., and Eastburn, D. M. 1997. Evaluation of inoculation methods for screening horseradish cultivars for resistance to Verticillium dahliae. Plant Dis. 81:356-362.

3. Atibalentja, N., and Eastburn, D. M. 1998. Verticillium dahliae resistance in horseradish germplasm from the University of Illinois collection. Plant Dis 82:176-180.

4. Babadoost, M., Chen, W., Bratsch, A. D., and Eastman, C. E. 2004. Verticillium longisporum and Fusarium solani: two new species in the complex of internal discoloration of horseradish roots. Plant Pathol. 53:669-676.

5. Babadoost, M., Chen, W., Bratsch, A. D., and Write, C. L. 2001. Incidence of horseradish disease in Illinois: a detailed field survey, 2000. Horseradish Res. Rev. Proc. Horseradish Grow. School 2001:9-13.

6. Barnett, H. L., and Hunter, B. B. 1998. Illustrated Genera of Imperfect Fungi, Fourth Edition. American Phytopathological Society, St. Paul, MN.

7. Booth, C. 1972. The Genus Fusarium. Surrey. CMI, Kew, UK.

8. Chun, J. 1995. Computer assisted classification and identification of actinomycetes. Ph.D. thesis, University of Newcastle. Newcastle upon Tyne, UK.

9. Courter, J. W., and Rhodes, A. M. 1969. Historical notes on horseradish Econ. Bot. 23:156-164.

10. Eastburn, D. M., and Chang, R. J. 1994. Verticillium dahliae: a causal agent of root discoloration of horseradish in Illinois. Plant Dis. 78:496-498.

11. Eranthodi, A., Babadoost, M., and Trierweiler, B. 2010. Thermotherapy for control of fungal pathogens in propagative rootstocks of horseradish. HortScience 45:599-604.

12. Geiser, D. M., Jimenez-Gasco, M. d. M., Kang, S., Makalowska, I., Veeraraghavan, N., Ward, T. J., Zhang, N., Kuldau, G. A., and O'Donnell, K. 2004. Fusarium-ID v. 1.0: a DNA sequence database for identifying Fusarium. Eur. J. Plant Pathol. 110:473-479.

13. Gerber, J. M., Doll, C. C., Simons, R. K., and Fillingim, K. E. 1983. Internal discoloration of horseradish-development of symptoms. Univ. Ill. Veg. Res. Rep. Hortic. Ser. 47:34-37.

14. Gerlach, W., and Nirenberg, H. I. 1982. The genus Fusarium-a pictorial atlas. Mitt. Biol. Bundesanst. Land Forstwirsch. Berlin-Dahlem 209:1-406.

15. Hall, T. A. 1999. BioEdit: a user-friendly biological sequence alignment editor and analysis program for Windows 95/98/NT. Nucleic Acid Symp. Ser. 41:95-98.

16. Hamini-Kadar, N., Edel-Hermann, V., Gautheron, N., and Steinberg, C. 2010. First report of Fusarium commune and Fusarium redolens causing crown and root rot on tomato in Algeria. BSPP, New Dis. Rep. 22:3. http://www.ndrs.org.uk/article.php?id=022003

17. Kadow, K. J., and Anderson, H. W. 1940. A study of horseradish diseases and their control. Univ. Ill. Agric. Exp. Stn. Bull. 496:529-583.

18. Kim, M.-S., Stewart, J., Kasten, R., and Klopfenstein, N. B. 2012. Occurrence of the root rots pathogen, Fusarium commune, in forest nurseries of the Midwestern and Western United States. J. Phytopathol. 160:112-114.

19. Leslie, J. F., and Summerell, B. A. 2006. The Fusarium Laboratory Manual Blackwell Publishing, Ames, IA.

20. Li, K. N., Rouse, D. I., and German, T. L. 1994. PCR primers that allow intergeneric differentiation of ascomycetes and their application to Verticillium spp. Appl. Environ. Microbiol. 60:4324-4331.

21. Mueller, J. P., Percich, J. A., and Mitchell, J. E. 1982. Root deterioration associated with Verticillium wilt of horseradish. Plant Dis. 66:410-414.

22. O'Donnell, K., Kistler, H. C., Cigelnik, E., and Ploetz, R. C. 1998. Multiple evolutionary origins of the fungus causing Panama disease of banana: concordant evidence from nuclear and mitochondrial gene genealogies. Proc. Natl. Acad. Sci. USA 95:2044-2049.

23. Percich, J. A., and Johnson, D. R. 1990. A root rot complex of horseradish. Plant Dis. 74:391-393.

24. Potschke, A. 1923. Uber das Scharzwerden des Meerrettichs (On the black discoloration of horseradish). Mitt. Biol. Reichsanst. Land Forstwirtsch. 11:337-338.

25. Raju, B. C., Nyland, G., Backus, E. A., and McLean, D. L. 1981. Association of a spiroplasma with brittle root of horseradish. Phytopathology 71:1067-1072.

26. Rhodes, A. M. 1977. Horseradish-Problems and Research in Illinois. Pages 137-147 in: Crop Resources. D. S. Seigler, eds. Academic Press, Inc., New York.

27. Shehata, A., Mulwa, R. M. S., Babadoost, M., Uchanski, M., Norton, M. A., Skirvin, R. M., and Walters, S. A. 2009. Horseradish: botany, horticulture, breeding. Hortic. Rev. 35:221-262.

28. Skovgaard, K., Rosendahl, S., O'Donnell, K., and Nirenberg, H. I. 2003. Fusarium commune is a new species identified by morphological and molecular phylogenetic data. Mycologia 95:630-636.

29. Stewart, J. E., Abdo, Z., Dumroese, R. K., Klopfenstein, N. B., and Kim, M S. 2011. Virulence of Fusarium oxysporum and F. commune to Douglas-fir (Pseudotsuga menziesii) seedlings. For. Pathol. http://onlinelibrary.wiley. 
com/doi/10.1111/j.1439-0329.2011.00746.x/full

30. Stewart, J. E., Kim, M. S., James, R. L., Dumroese, R. K., and Klopfenstein, N. B. 2006. Molecular characterization of Fusarium oxysporum and Fusarium commune isolates from a conifer nursery. Phytopathology 96:11241133.

31. Thompson, J. D., Gibson, T. J., Plewniak, F., Jeanmougin, F., and Higgins, D. G. 1997. The CLUSTAL_X windows interface: flexible strategies for multiple sequence alignment aided by quality analysis tools. Nucleic Acids Res. 25:4876-4882.

32. White, T. J., Bruns, T., Lee, S., and Taylor, J. 1990. Amplification and direct sequencing of fungal ribosomal RNA genes for phylogenetics. Pages 315322 in: PCR Protocols: A Guide to Methods and Applications. M. A. Innis, D. H. Gelfand, J. J. Sninsky, and T. J. White, eds. Academic Press, New York. 